\title{
Investigation of biosecurity risk organisms for the plant and environment domains in New Zealand for 2008 and 2009
}

\author{
K.J. Froud and M.S. Bullians \\ Ministry of Agriculture and Forestry, PO Box 2095, Auckland, New Zealand \\ Corresponding author:froudk@maf.govt.nz
}

\begin{abstract}
The Ministry of Agriculture and Forestry Biosecurity New Zealand runs several surveillance programmes to detect new or emerging risk organisms in New Zealand. Reporting of these organisms is through the exotic disease and pest emergency hotline. Notifications received through the hotline are screened and investigated to determine if they pose a risk to New Zealand's core biosecurity values (economic, environmental, human health and cultural). Significant numbers of notifications are received each year. Data detailing the notification and investigation of suspect risk organisms in the plants and environment domains for the last 2 years are presented and compared with previously published data. The trend in notifications and the resulting outcomes of investigations are discussed.
\end{abstract}

Keywords incursion, investigation, detection, biosecurity, passive surveillance, risk assessment, invasive, exotic.

\section{INTRODUCTION}

The New Zealand biosecurity system aims to enable safe trade and protect New Zealanders, our unique natural resources and our plants and animals from harmful pests and diseases (Anon. 2003). The Ministry of Agriculture and Forestry Biosecurity New Zealand (MAFBNZ) is charged with managing the biosecurity system across the border and post-border areas. In the border area this includes offshore regulatory and inspection activities aimed at reducing the risks posed by trade with other countries as well as border activities aimed at risk profiling and inspection to manage the risk pathways for new risk organisms arriving in NZ. Activities in the post-border area include detecting, investigating, diagnosing, responding and managing those organisms that have entered or established in New Zealand and pose a biosecurity risk along with established organisms that pose an emerging risk. Surveillance to detect new organisms increases the probability of early detection of pests and diseases establishing, and includes both targeted (Clift 2008; Anon. 2009a) and passive surveillance programmes, the latter of which is delivered via notifications to the MAFBNZ exotic disease and pest hotline 080080 9966 . A regulated duty to report new, unwanted and notifiable organisms is also provided under sections 44 and 46 of the Biosecurity Act 1993 to enable the passive surveillance system to be effective in New Zealand. Internationally, coordinated passive surveillance is becoming a mainstay for early detection of pests and diseases. Programmes 
include the Australian National Plant Surveillance Reporting Tool (Anon. 2009b), and the United States First Detector programme (Fletcher \& Stack 2007). The success of these systems hinge on the capability that public participants, growers, farmers, scientists and veterinarians have for field recognition of pests and diseases and the epidemiological investigation and diagnostics capability within the system (Morse 2002). An effective passive surveillance system requires a wide net to be cast initially in order to encourage notifications that can then be eliminated based on scientific risk assessment. New Zealand has a wellinformed population regarding biosecurity and the risk exotic organisms pose to New Zealand, both within the general public and those involved in the environment and primary sectors. In a recent Neilson survey assessing perceptions of the most important issues facing New Zealand, biosecurity came second to reducing domestic violence and just above reducing the road toll as a concern to New Zealanders (A. Wright, MAFBNZ, unpublished data). Of the respondents $92 \%$ were aware that MAF is responsible for responding to new pests or diseases and $91 \%$ felt that they would report a suspicious new pest or disease (A. Wright, MAFBNZ, unpublished data). New Zealand is likely to be well placed to run an effective passive surveillance system because of this awareness. Notifications received of new and emerging biosecurity risks are investigated by MAFBNZ and scientifically assessed based on risk. Initial assessment is based on eliminating common existing organisms that pose no new threat from the widely-cast net, followed by diagnostics and investigation into the current state or likelihood of establishment or spread, the consequences an organism may have on our values (environment, economic, human health and cultural) and opportunities for management.

This paper describes the patterns in notifications from different sectors and reporter types and the investigation and biosecurity outcomes from these reports using data detailing the notification and investigation of suspect risk organisms for the last 2 years with some comparison with previously published data (Froud et al. 2008) for New Zealand.

\section{METHODS}

\section{Exotic disease and pest emergency hotline 0800809966 investigation data}

Data from the MAFBNZ Incursion Investigation Groups plants and environment investigation register were extracted and analysed from 1 January 2008 to 31 December 2009. For each notification, data were collected for comparison under the domain and sector that the notification originated from. The domains that are included in this analysis are the Plant Health domain (pests, diseases and weeds of productive plants and plant-based genetically modified organisms) and the Environment domain (plant or animal pests and diseases that affect terrestrial or freshwater environments excluding vertebrates and diseases of animals). In addition MAFBNZ undertakes investigations within the Animal Health domain (pests and diseases of farmed or domesticated animal species including honeybees and vertebrate pests) and the Marine domain, but these data are not included in this analysis. There are four sectors from which we received notifications. These were industry (productive plant industries and consultants), biosecurity service providers (suppliers of border inspection/clearance activities, such as MAF Quarantine Inspectors or accredited persons at transitional facilities; biosecurity surveillance or response service providers and regional council biosecurity staff), the scientific community (Crown Research Institutes, MAF scientists, Department of Conservation, independent scientists, universities, museums and other scientific organisations) and the general public (people not identifying themselves as members of the scientific community, industry or biosecurity providers).

\section{Risk assessment pathway}

In addition to notification data, data were collected at each risk assessment point during an investigation, at the conclusion of the investigation and following decision-making regarding moving into a response. This risk assessment pathway is illustrated in Figure 1 and shows the funnelling effect from an initial wide notification base down to a small number of investigations where a residual risk remained and a full biosecurity 
response was required to manage the risk. The data included in this analysis refer to the diagnostic result, the biosecurity risk assessment and, where a risk was identified and remained at the conclusion of the investigation, what the final investigation outcome was. Details of the criteria used for analysis in each of these are below.

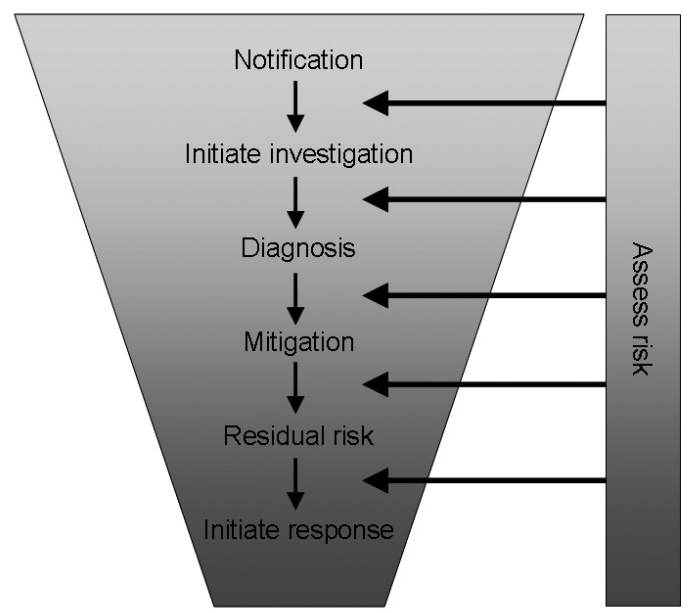

Figure 1 Risk assessment pathway undertaken at decision points during an investigation into new or emerging risk organisms notified to MAFBNZ.

\section{Diagnostic result}

- Inconclusive - cases where no diagnosis can be made, for example only juveniles present (and no sequence data available), no specimen available for identification or the notifier failed to submit it.

- Negative - not a new (as defined by the HSNO Act 1996) or unwanted organism (as defined by the Biosecurity Act 1993), including notifications where the organism was found to be already part of the described New Zealand flora or fauna.

- Positive-wherea new organism not previously described or known to be established in New Zealand is identified or organisms known to be present in New Zealand that are listed on the unwanted organisms register, e.g. redback spiders (Latrodectus hasseltii).

\section{Biosecurity risk assessment}

These assessments refer to the presence of a new or emerging biosecurity issue and the risk it may pose to New Zealand's biosecurity values. They are divided into the following five categories:

- No biosecurity issue - the investigation finds that no biosecurity issue exists.

- Biosecurity issue, no biosecurity risk - the investigation finds some biosecurity issue exists, such as a previously un-described indigenous species, but the investigation concludes that there is no new biosecurity risk posed by that organism.

- Biosecurity issue, biosecurity risk addressed the investigation finds a biosecurity issue exists but actions taken during the investigation are believed to have effectively mitigated the biosecurity risk.

- Biosecurity issue, pathway risk remains - the investigation finds some biosecurity issue exists. MAFBNZ may have taken some actions to address the immediate biosecurity risk but these have not sufficiently addressed the risk of future events on the pathway in question. This information is fed back to MAFBNZ Border Biosecurity groups.

- Biosecurity issue, biosecurity risk remains - the investigation finds a biosecurity issue exists. The investigation team may have taken some actions against the risk but these have not, in their view, removed the risk and a wider MAFBNZ response team may be required to manage the risk by initiating a response.

\section{Investigation outcomes}

At the completion of an investigation where a biosecurity issue was determined and a risk remained, a decision has to be made to respond or not to respond. Therefore, one of the following four outcomes must be selected:

- No action taken - the investigation confirms the presence of an unwanted or new organism, and no action is required or taken to limit harm or prevent establishment.

- Urgent measures taken to limit harm - the investigation confirms the presence of an unwanted or new organism, and urgent 
actions have been taken that limit the potential for harm while recognising that a propagative organism could remain (e.g. an incomplete product recall).

- Urgent measures taken to prevent establishment - the investigation confirms the presence of an unwanted or new organism, and urgent actions are taken that ensure no propagative organisms remain.

- Biosecurity response initiated - any investigation that results in the initiation of a biosecurity response by MAFBNZ.

\section{Data analysis}

Data were analysed using Microsoft Excel.

\section{RESULTS AND DISCUSSION}

In the last 2 calendar years (2008-2009) MAFBNZ received 26,289 calls to the 080080 9966 exotic disease and pest hotline (13653 and 12636 respectively) (Nicci Rowswell, MAFBNZ, personal communication). Of these, 7350 were referred on by the call centre for further screening in the plant health and environment domains. Of those, 6197 were immediately eliminated as not representing a biosecurity issue, the remaining 1153 notifications were investigated by the MAFBNZ Incursion Investigation Group's Plant and Environment team (679 and 474 for 2008 and 2009 respectively) over this period (Table 1 ).

When 2009 data are compared to data from 2008 and previous years (Froud et al. 2008) there was a reduction in the number of investigations by MAFBNZ initiated from notifications, due to improved screening and initial risk assessment procedures informed by 6 years of data, particularly from notifications received from the general public (Table 1).

There was a reduction in the number of reports investigated from biosecurity service providers in the environmental domain in 2009 (Table 1). On examination of the raw data this was entirely due to a much lower number of investigations resulting from exotic ants detected as part of MAFBNZ Invasive Ant Surveillance programmes in 2009 as opposed to 2008 ( 3 and 44 respectively). New mitigation measures for the management of invasive ants from the Pacific are reported elsewhere (Burnip et al. 2007; O'Connor \& Weston 2010) and are likely to account for some of the overall reduction within the environment domain. There are variations in the number of investigations resulting from the science community over time. The figures for 2006 and 2007 are 54 and 41 respectively (K. Froud, MAFBNZ, unpublished data) and for 2008 and 2009 are 76 and 57 respectively. These variations are largely due to the completion dates of research programmes undertaking baseline surveillance.

The results of these investigations can be measured by a diagnostic result, biosecurity risk assessment or investigation outcome, each of which takes us further down the risk assessment pathway.

\section{Diagnostic results}

Looking at the diagnostic results to investigations, the likelihood of different reporting sectors to report a case that is positive for a risk organism

Table 1 Numbers of investigations initiated within the plant health and environment domains over 2008 and 2009.

\begin{tabular}{lrrrrrrrr}
\hline & \multicolumn{2}{c}{2008} & & \multicolumn{2}{c}{2009} & & \\
\cline { 2 - 3 } Sector making notification & $\begin{array}{c}\text { Environ- } \\
\text { ment }\end{array}$ & Plant health & & $\begin{array}{c}\text { Environ- } \\
\text { ment }\end{array}$ & Plant health & Total & $\begin{array}{r}\text { Percent } \\
\text { of total }\end{array}$ \\
\hline Biosecurity service providers & 65 & 42 & & 24 & 63 & 194 & 16.8 \\
General public & 191 & 293 & & 130 & 191 & 805 & 69.8 \\
Industry & 2 & 10 & & 0 & 9 & 21 & 1.8 \\
Science community & 6 & 70 & & 6 & 51 & 133 & 11.5 \\
Total & $\mathbf{6 7 9}$ & & & $\mathbf{4 7 4}$ & & $\mathbf{1 1 5 3}$ & \\
\hline
\end{tabular}


Table 2 Diagnostic results of investigations undertaken within the plants and environment domains over 2 years from different sectors notifying MAFBNZ.

\begin{tabular}{|c|c|c|c|c|}
\hline Sector making report & Negative & Positive (\%) & Inconclusive & Total \\
\hline Biosecurity service providers & 48 & $130(67.0)$ & 16 & 194 \\
\hline General public & 429 & $205(25.5)$ & 172 & 805 \\
\hline Industry & 5 & $15(71.4)$ & 1 & 21 \\
\hline Science community & 26 & $103(77.4)$ & 4 & 133 \\
\hline Total & 507 & $453 \quad(39.3)$ & 194 & 1153 \\
\hline
\end{tabular}

or species not previously recorded from New Zealand can be assessed (Table 2).

These data indicate that passive surveillance and a regulatory requirement to report new organisms is resulting in the detection of new organisms (or positives) when the net is cast wide, which is the primary aim of this type of system. However, while the high percentage of positive diagnostic results in the table above indicates a large number of new organisms were detected they do not necessarily represent a high number of biosecurity risks that would pose significant impacts to New Zealand's values. The risk and impact of a new organism is not often clear after diagnosis and further investigation and risk assessment is required to assess the biosecurity risk to New Zealand's values before a recommendation to respond or not can be made. This leads further down the risk assessment pathway in the system as investigations do not just seek to determine the presence of an exotic organism but also to assess the risk posed by the organism and to determine if urgent treatments can be used to mitigate the risk organism to stop it from establishing in New Zealand.

\section{Biosecurity risk assessment}

Table 3 shows the biosecurity risk categories at the conclusion of an investigation. There is not a one-to-one relationship with risk organisms and positive diagnostic results, as the positive diagnostic result informs only part of the bigger picture within an investigation and often evidence collected during an investigation will indicate a risk exists even for a negative diagnostic result (see garlic aphid example below) and that a risk does not exist for a positive result.

Despite the fact that $39.3 \%$ of cases resulted in a positive diagnosis for a new organism, following assessment of the biosecurity risk the organism poses to $\mathrm{NZ}$ and after urgent mitigation of risks, only $4.9 \%$ of investigations move on from the investigation process into further assessment and management under the MAFBNZ response system.

Of those excluded from posing a biosecurity risk, many of the positive results in Table 2 indicate the previously unrecorded baseline state of New Zealand's biodiversity and describe organisms that have long been present (and managed) but had remained undiagnosed. Equally in some instances where a diagnostic result is negative or inconclusive, it can still be decided that a biosecurity risk is present and needs to be mitigated. For example, a detection of live garlic aphids (Neotoxoptera formosana) on imported garlic is negative for an exotic organism (garlic aphids are well established in New Zealand) but indicates a pathway risk for introduction of associated organisms on a product that requires fumigation under the Import Health Standard, therefore this indicates a treatment failure. This information is fed back into the MAFBNZ risk profiling system, which informs the management of biosecurity risks at the border. In $23.5 \%$ of cases a biosecurity issue is present but urgent measures are undertaken to address the risk (Table 3 ). These mostly represent hitchhiker pests associated with imported items and single nest ant incursions, which are immediately mitigated during the course of the investigation through 
appropriate treatments (e.g. recall and treatment of wooden furniture and toxic baiting with follow up surveillance of ant nests) and show that management of biosecurity risks beyond the border, can be effective.

As was reported in an earlier analysis by Froud et al. (2008) the general public were once again significant participants in notifying biosecurity risks associated with recent importation pathways. As shown in Table 3 the general public contributed to $255(188+67)$ instances where a risk organism was detected and urgent mitigation measures were successful in eliminating the risk prior to potential establishment in New Zealand and all of these informed border risk profiling.

Again as was the trend in earlier data (Froud et al. 2008) the more serious risks that were not immediately linked to an importation pathway, and therefore harder to mitigate, were detections of newly invading or unrecorded established organisms, which were identified and reported by biosecurity service providers and the science community.

\section{Biosecurity outcomes}

Looking specifically at those cases that represent a residual risk where the risk was not resolved or addressed during investigation and where a biosecurity risk remained $(\mathrm{n}=57)$ (Table 3$)$, we can break these data down into biosecurity outcomes to provide further information on how the MAFBNZ response system dealt with these cases (Table 4).

No action was taken for $43.9 \%$ of these cases and in almost all of these cases this was due to the fact that the organism was already very widespread at the time of the detection and subsequent notification (not always timely). Many of these organisms had been listed as unwanted organisms for imports into $\mathrm{NZ}$ and therefore required removal from this list on proof of an established presence within NZ. In the 14 cases where urgent measures were used to limit harm or prevent establishment, these cases were significant enough to require an immediate wider biosecurity response approach to mitigating the risk (e.g. on detection of Thrips palmi on imported flowers from a new source, MAFBNZ immediately changed procedures at the border to ensure that this risk was mitigated). The remaining 18 risk organisms triggered a full MAFBNZ response. These included responses to the Australian subterranean termite Coptotermes acinaciformes in the South Island, Candidatus Liberibacter solanacearum in tomatoes (and further notifications in capsicum and potatoes that were included into the same response), tropical weeds in coco-peat, two new/emerging sub-tropical weeds that have established, Chinese knot-weed (Persicaria chinensis) in Auckland and the bat-winged passion flower (Passiflora apetala)

Table 3 Biosecurity risk assessment categories at the conclusion of all investigations undertaken within the plant health and environment domains over 2 years from different sectors notifying MAFBNZ.

\begin{tabular}{lcccccc}
\hline & \multicolumn{6}{c}{ Status of biosecurity issue } \\
\cline { 2 - 7 } & No issue & No risk & $\begin{array}{c}\text { Risk } \\
\text { addressed }\end{array}$ & $\begin{array}{c}\text { Pathway } \\
\text { risk } \\
\text { remains }\end{array}$ & $\begin{array}{c}\text { Risk } \\
\text { remains }\end{array}$ & $\begin{array}{c}\text { \% Cases with } \\
\text { residual risk }\end{array}$ \\
Sector making remains)
\end{tabular}

${ }^{1}$ Pathway risk remains indicates that while the immediate risk posed by the organism was addressed during the investigation, additional feedback indicating a pathway risk was given to MAFBNZ Border risk profiling teams, therefore these results are excluded from the residual risk results. 
Table 4 Biosecurity system outcomes for investigations that resulted in the identification of biosecurity risk remaining from the plant health and environment domains over 2 years from different sectors notifying MAFBNZ.

\begin{tabular}{|c|c|c|c|}
\hline Sector making report & No action taken & $\begin{array}{c}\text { Urgent measures to } \\
\text { limit harm or prevent } \\
\text { establishment }\end{array}$ & Response initiated \\
\hline Biosecurity service providers & 9 & 4 & 7 \\
\hline General public & & 7 & 4 \\
\hline Industry & 3 & & 2 \\
\hline Science community & 13 & 3 & 5 \\
\hline Total (\%) & $25(43.9)$ & $14(24.6)$ & $18(31.6)$ \\
\hline
\end{tabular}

in Auckland and Northland and kauri dieback (Phytophthora taxon Agathis).

The MAFBNZ notification and investigation system is aimed at detecting new or emerging harmful pests and diseases early enough to eradicate them. Kriticos et al. (2005) state "The estimate that $5 \%$ of pest organisms are eradicable at the time of their discovery in New Zealand is optimistic and the real figure is probably lower". In the present paper, of the 57 organisms where residual risk remained following assessment and mitigation, only 30 were found without a recent import pathway and were therefore similar to the description of a new pest in Kriticos et al. (2005). Of these 30 risk organisms, 2 genetically modified plant incursions were eradicated, 1 weed is under eradication, 1 weed is currently under control, 2 further weeds are being dealt with under the National plant pest accord, 1 termite incursion is successfully being eradicated and another 1 is under control (Pearson et al. 2010). This gives $4 / 30$ on track for eradication, a percentage of $13.3 \%$, which is significantly higher than that estimated by Kriticos et al. (2005). However, 30 new risk organisms (including 4 weeds) is also less than Kriticos et al. (2005)'s estimate of approximately 45 new pests per annum excluding weeds (estimate of 542 from 2005-2017). Recent research in eradication technologies have yet to be proven but may bring greater benefits.

\section{CONCLUSIONS}

The maintenance and development of monitoring systems and surveillance datasets (such as the
MAFBNZ Investigation Dataset) is crucial if emerging biosecurity risks are to be identified at early stages of introduction and establishment (MacLeod et al. 2010). In New Zealand we are fortunate enough to have a centralised biosecurity agency and can collect and use new incursion and emerging risk data to show trends, target surveillance, research and preparedness activities, and predict and mitigate pathway risks. Despite extensive searches comparable published data from another country could not be found to compare the success of MAFBNZ's passive surveillance and investigation system with similar systems elsewhere. Where similar systems do exist, such as Australia, their investigation and diagnosis is undertaken by a range of state, territories and federal government agencies (Anon. 2009b) and combined data are not available.

New Zealand's biosecurity surveillance system is the first line of defence in detecting the presence of a new or emerging risk organism past the border. Maximising surveillance effectiveness by using both active and passive surveillance strategies increases the probability of detecting new or emerging harmful pests and diseases early enough to eradicate them. The surveillance and investigation system outlined above uses many eyes and ears within New Zealand and uses a riskbased approach to screen and mitigate biosecurity risks along the risk assessment pathway. The passive surveillance system is not perfect, however, and many organisms are not detected until it is too late for eradication or effective management. In these situations it must be accepted that the 
impacts of new pests and diseases to New Zealand are cumulative over time and that one problem does not disappear when another arrives (Goldson et al. 2005). Further analysis of investigation data is recommended to determine the characteristics of risk organisms that are detected (in a timely way) using passive surveillance versus those that are not. This will help to inform where targeted surveillance may be more appropriate or where improvements to passive surveillance can be made. Anticipating pest incursion is critical in minimising loss of production (Goldson et al. 2005) and impacts to the environment, and improving early detection through increased awareness within key notifiers (biosecurity service providers, the scientific community and industry) will improve New Zealand's ability to eradicate and respond to new risks. The MAFBNZ biosecurity surveillance strategy aims to address these gaps over the next 10 years (Anon. 2009a).

\section{ACKNOWLEDGEMENTS}

We would particularly like to thank the MAFBNZ Plant and Environment Incursion Investigation and Diagnostic teams and the Response, Surveillance and Pest Management Groups who all contributed to these data. Thanks to George Gill and Katherine Clift for valuable comments on improving the manuscript and to all of the notifiers to the MAF exotic disease and pest hotline (0800 809966 ).

\section{REFERENCES}

Anon. 2003. Tiakina Aotearoa, Protect New Zealand, the Biosecurity strategy for New Zealand. Biosecurity Council, Wellington, New Zealand. 63 p.

Anon. 2009. Biosecurity Surveillance Strategy 2020. Ministry of Agriculture and Forestry, Wellington, New Zealand. $51 \mathrm{p}$.

Anon. 2009. National Plant Health Status Report (08/09). Plant Health Australia, Canberra, ACT. 184 p.

Burnip GM, Sarty M, Gunawardana D, Green O 2007. A success story: early detection of exotic ants. New Zealand Plant Protection 60: 313 (Abstract).
Clift K 2008. What does the future hold for surveillance? In: Froud KJ, Popay AI, Zydenbos SM ed. Surveillance for biosecurity: Preborder to pest management. New Zealand Plant Protection Society Inc., Hastings, New Zealand. Pp. 77-79.

Fletcher J Stack JP 2007. Plant Biosecurity Infrastructure for disease surveillance and diagnostics. In: Lemon SM. Institute of Medicine. Global infectious disease surveillance and detection: Assessing the challenges - Finding solutions. Workshop summary. The National Academies Press, Washington, DC. Pp. 95-106.

Froud KJ, Oliver TM, Bingham PC, Flynn AR, Rowswell NJ 2008. Passive surveillance of new exotic pests and diseases in New Zealand. In: Froud KJ, Popay AI, Zydenbos SM ed. Surveillance for biosecurity: Preborder to pest management. New Zealand Plant Protection Society Inc., Hastings, New Zealand. Pp. 97-110.

Goldson SL, Rowarth JS, Caradus JR 2005. The impact of invasive invertebrate pests in pastoral agriculture: a review. New Zealand Journal of Agricultural Research 48: 401-415.

Kriticos DJ, Phillips CB, Suckling DM 2005. Improving border biosecurity: potential economic benefits to New Zealand. New Zealand Plant Protection 58: 1-6.

MacLeod A, Pautasso M, Jeger MJ, HainesYoung R 2010. Evolution of the international regulation of plant pests and challenges for the future of plant health. Food Security 2: 49-70.

Morse SS 2002. The vigilance defence. Scientific American 287(4): 88-89.

O'Connor S, Weston P 2010. Preventing the international spread of invasive ants through implementation of offshore biosecurity risk management policy. In: Lach L, Parr CL, Abbott K ed. Ant Ecology. Oxford University Press, Oxford. Pp. 242-243.

Pearson HG, Bennett SJ, Philip BA, Jones DC 2010. The Australian dampwood termite, Porotermes adamsoni, in New Zealand. New Zealand Plant Protection 63: 241-247. 